\title{
Responder de Cães por Exclusão em Tarefas de Discriminação Condicional
}

\author{
Maria Clara de Freitas, Thaize de Souza Reis, Táhcita Medrado Mizael \& \\ Camila Domeniconi" \\ Universidade Federal de São Carlos, São Carlos, Brasil
}

\begin{abstract}
RESUMO
O presente estudo treinou o responder por exclusão em cães por meio do ensino de discriminações condicionais entre objetos e seus respectivos nomes ditados e avaliou empiricamente a influência neste desempenho de dicas sociais humanas (gestos direcionados aos estímulos) quando estas eram direcionadas ao estímulo contrário. Os dois animais demonstraram rápida aquisição de controle pelo estímulo novo, controle que se manteve mesmo com a inserção de dicas sociais contrárias ao estímulo ditado (instruir oralmente a seleção de $\mathrm{S}+$, porém apontar para $\mathrm{S}$-). Foi evidente a influência das dicas sociais contrárias quando os estímulos eram familiares, com ruptura do controle preestabelecido. Discute-se a relevância deste estudo na comparação de diferentes aspectos do ambiente no comportamento canino, e enfatiza-se a necessidade de incluir sondas de controle pela novidade, para pesquisas futuras.
\end{abstract}

Palavras-chave: exclusão; aprendizagem animal; discriminação condicional; cães.

\section{ABSTRACT \\ Conditional Discrimination Responding by Exclusion in Dogs}

This study trained the responding by exclusion in dogs, based on a conditional discrimination between dictated names and objects, and empirically evaluated the influence in that performance of human social cues (gestures directed to stimuli) towards the opposite stimulus. As a result, both animals showed rapid acquisition of control by the new stimulus, a pattern that persisted even after the inclusion of conflicting social cues toward the wrong stimulus (orally instructing the selection of $\mathrm{S}+$, but pointing to the S-). The influence of conflicting social cues when the stimuli involved were familiar is clear, a pattern showed by the disruption of pre-established control. We discuss the relevance of this study in the comparison of different aspects of the environment on the behavior of dogs, and the need to include control probes for novelty in future research is emphasized.

Keywords: exclusion; animal learning; conditional discrimination; dogs.

A discussão sobre as semelhanças existentes entre humanos e não humanos quanto a algumas habilidades específicas é habitual tanto no âmbito científico quanto fora dele. Um ponto de interesse recente neste contexto se refere às habilidades caninas e sua relação com as habilidades humanas. Muitas evidências da proximidade entre homens e cães (algumas vezes considerada mais clara e convincente que a de homens e primatas não humanos) vêm de pesquisas que investigam a sensibilidade dos cães a dicas sociais humanas (Call, Bräuer, Kaminski, \& Tomasello, 2003; Hare,
Brown, Williamson, \& Tomasello, 2002; Hare \& Tomasello, 2005; McKinley \& Sambrook, 2000; Miklósi, Polgárdi, Topál, \& Csányi, 2000; Miklósi, Topál, \& Csányi, 2001; Udell \& Wynne, 2008).

Entre os seres humanos, gestos como movimentos de cabeça ou olhares, mesmo que sutis, podem funcionar como importantes formas de comunicação. Algumas descobertas recentes sugerem que essas formas de comunicação parecem funcionar também entre humanos e cães, mais especificamente, que cães são bastante sensíveis a dicas fornecidas por seres humanos. 
Para avaliar tal habilidade, em geral, os estudos empregam a tarefa de escolha do objeto. Nesse tipo de tarefa, comida ou outro objeto reforçador para o cão (brinquedo, por exemplo) é escondido em uma de duas ou mais localizações sem que o cão veja. Em seguida, o dono, o experimentador ou alguma outra pessoa indica ao cão a localização do objeto escondido. As dicas podem envolver olhar ou virar a cabeça em direção ao objeto, curvar-se em direção a ele ou mesmo apontar a localização correta. Os resultados mostram que os cães são muito bem sucedidos em usar as dicas para encontrar os objetos escondidos. Essas habilidades foram encontradas mesmo em filhotes com menos de seis meses de idade e com pouco contato com seres humanos (Call e cols., 2003).

A via inversa também tem sido estudada, e, com resultados similares, mostra que cães também parecem ser habilidosos em fornecer dicas para humanos. No estudo de Miklósi e colegas (2000), cães viam um objeto ser escondido e em seguida deviam indicar ao dono (que não presenciara a cena e não sabia onde se encontrava o objeto) a localização do objeto. De acordo com os resultados, os donos foram capazes de localizar o objeto a partir das dicas fornecidas pelos cães, que, na presença do dono, olhava mais para ele e para a localização do objeto, bem como alternava mais o olhar entre esses dois alvos.

Uma hipótese para explicar essa sensibilidade mútua é a própria domesticação canina. Isto porque, além de compartilhar com os cães o mesmo ambiente há milhares de anos (há indícios de que a convivência entre as espécies tenha por volta de $100 \mathrm{mil}$ anos, Vila e cols., 1997), os seres humanos têm sido os responsáveis pelo controle de reforços aos quais estes animais têm acesso ao longo de toda a vida, como comida e água. Assim, os cães passam a responder não mais apenas de acordo com as contingências da natureza, mas sim, e mesmo preferencialmente, de acordo com aquelas engendradas pelos humanos (Udell \& Wynne, 2008).

Além desta seleção ontogenética, os seres humanos têm sido responsáveis pelo controle filogenético dos animais, que são selecionados deliberadamente por meio do cruzamento planejado para refinamento de características e comportamentos específicos e desejados pelos criadores (Udell \& Wynne, 2008). Vista desta forma, a domesticação explica grande parte da disposição dos cães em responder às contingências humanas (Udell \& Wynne, 2008), já que cães obedientes e responsivos provavelmente são preferidos tanto para a reprodução quanto para os cuidados do dono.
As descobertas sobre a sensibilidade dos cães a dicas sociais humanas colocam à prova um entendimento de muitos estudiosos: o de que a capacidade de compreender dicas sutis e compartilhar a atenção com o outro é uma habilidade típica e unicamente humana (Tomasello, 1999). Um estudo que teve grande contribuição nessa área demonstrou que um border collie chamado Rico apresentava habilidades comunicativas elaboradas de reconhecimento de objetos pelo nome e inclusive comportamentos indicativos de aprendizagem por exclusão (Kaminski, Call, \& Fischer, 2004).

O responder por exclusão, definido brevemente como a escolha da alternativa correta pela exclusão das demais alternativas (Dixon, 1977), é um tipo de estratégia amplamente empregada no ensino de habilidades tipicamente linguísticas para seres humanos. Nestes estudos, geralmente, às pessoas (adultos, crianças e/ou pessoas com deficiências) são apresentados alguns estímulos conhecidos e apenas um estímulo novo, de forma que elas devem escolher este último quando lhes é ditado um nome inédito (e.g., Costa, 1999; Dixon, 1977; Ferrari, de Rose \& Mcllvane, 1993).

Bastante similar à habilidade exigida para as pessoas, a tarefa do experimento (Kaminski e cols., 2004) consistia na disposição de vários itens (objetos) em uma sala diferente da que o cão estava e na solicitação, pelo dono, que o cão buscasse um objeto com um nome até então inédito. Os resultados mostraram que o animal escolheu o objeto correto em sete de dez tentativas e demonstrou retenção deste padrão de resposta em três de seis tentativas dez semanas depois.

$\mathrm{O}$ experimento como um todo demonstrou que o cão associou padrões acústicos arbitrários (palavras ditadas por voz humana) a itens específicos de seu ambiente, com base na familiaridade dos demais itens, o que parece se encaixar da definição da aprendizagem por exclusão, como é realizada por seres humanos.

Outro estudo que utilizou o teste de exclusão com não humanos foi o de Aust e colegas (2008). Nesse estudo, em um procedimento de emparelhamento com o modelo computadorizado, apresentado a partir de telas sensíveis ao toque e em que os reforçadores eram liberados automaticamente a cada reposta correta, humanos (adultos e crianças) e não humanos (cães e pombos) foram treinados na discriminação de quatro figuras positivas (cuja escolha produzia o reforçador) e quatro negativas (cuja escolha não produzia o reforçador). Após o treino, eles eram submetidos a um teste de exclusão, em que um estímulo desconhecido 
aos participantes era apresentado em tentativas combinadas com estímulos negativos previamente treinados.

Os resultados mostraram que um dos seis pombos, metade dos seis cães e praticamente todos os humanos (crianças e adultos) recrutados para a pesquisa apresentaram aprendizagem por exclusão, uma contribuição importante para a generalização entre espécies, e uma indicação clara da superioridade do desempenho canino também neste tipo de tarefa frente a outros animais (Aust e cols., 2008).

Ainda que promissores, estes estudos tiveram poucos sujeitos, e, em um deles, o cão tinha uma história pouco comum de treino de discriminação de nomes. De fato, Rico, o cão (Kaminski e cols., 2004), foi ensinado desde pequeno por seus donos a buscar objetos nomeados por eles, tendo chegado, aos nove anos de idade, a reconhecer por nome cerca de 200 objetos, um vocabulário impressionante e comparável ao de uma criança de dois anos.

Baseado em evidências anteriores, pode-se concluir que existem indícios claros de que os cães demonstram o padrão de responder por exclusão similar ao encontrado com humanos (Kaminski e cols., 2004) além de também grande sensibilidade para responder sob controle de dicas sociais, emitidas por humanos (Call e cols., 2003). Diante destas considerações, a conclusão que se chega parece ser justamente a veemente necessidade de novas pesquisas que repliquem e desenvolvam estes procedimentos, e que verifiquem empiricamente qual dos dois controles de estímulo pode exercer maior influência no responder de cães: as dicas sociais ou o treino da discriminação condicional por exclusão.

Assim sendo, o presente estudo pretendeu avaliar influência de dicas sociais humanas no desempenho de três cães em tarefas de seleção de objetos familiares e seleção por exclusão. Para tanto, um procedimento de discriminação condicional estabeleceu a seleção de objetos sob controle de seus nomes ditados.
A possível influência das dicas sociais humanas pôde ser então, verificada, a partir da apresentação concomitante do nome ditado do objeto que o cão deveria selecionar e de uma dica (virar a cabeça em direção a, olhar ou apontar) em direção ao objeto contrário. Desta forma, as duas possíveis fontes controladoras do comportamento de escolha do animal, o nome ditado dos objetos familiares e novos (relações recém-ensinadas ao animal) e a dica humana (relação notoriamente importante no repertório canino), tornavam-se competitivas, possibilitando uma análise da relação entre elas, e de como uma pode exercer influência na outra.

\section{MÉTODO}

\section{Sujeitos}

Três cães participaram da pesquisa: Xena, sem raça definida e com seis meses de idade, Pity e Sally, ambas da raça poodle, com 10 e 16 meses de idade, respectivamente, no início do experimento. Os animais foram selecionados de acordo com a disponibilidade dos donos para participarem do estudo.

\section{Situação Experimental}

As sessões experimentais foram realizadas nas casas dos donos dos animais e ocorreram de cinco a seis vezes por semana com duração de 10 a 15 minutos. Participavam da sessão o sujeito experimental, o experimentador e um ajudante de pesquisa. Os objetos eram dispostos no chão, e as tentativas eram filmadas por uma câmera posicionada para gravar os objetos e as respostas do animal.

A Figura 1 ilustra uma tentativa, com todos os participantes e suas posições, bem como as três colocações possíveis dos objetos: à direita, à esquerda e em frente ao experimentador. 


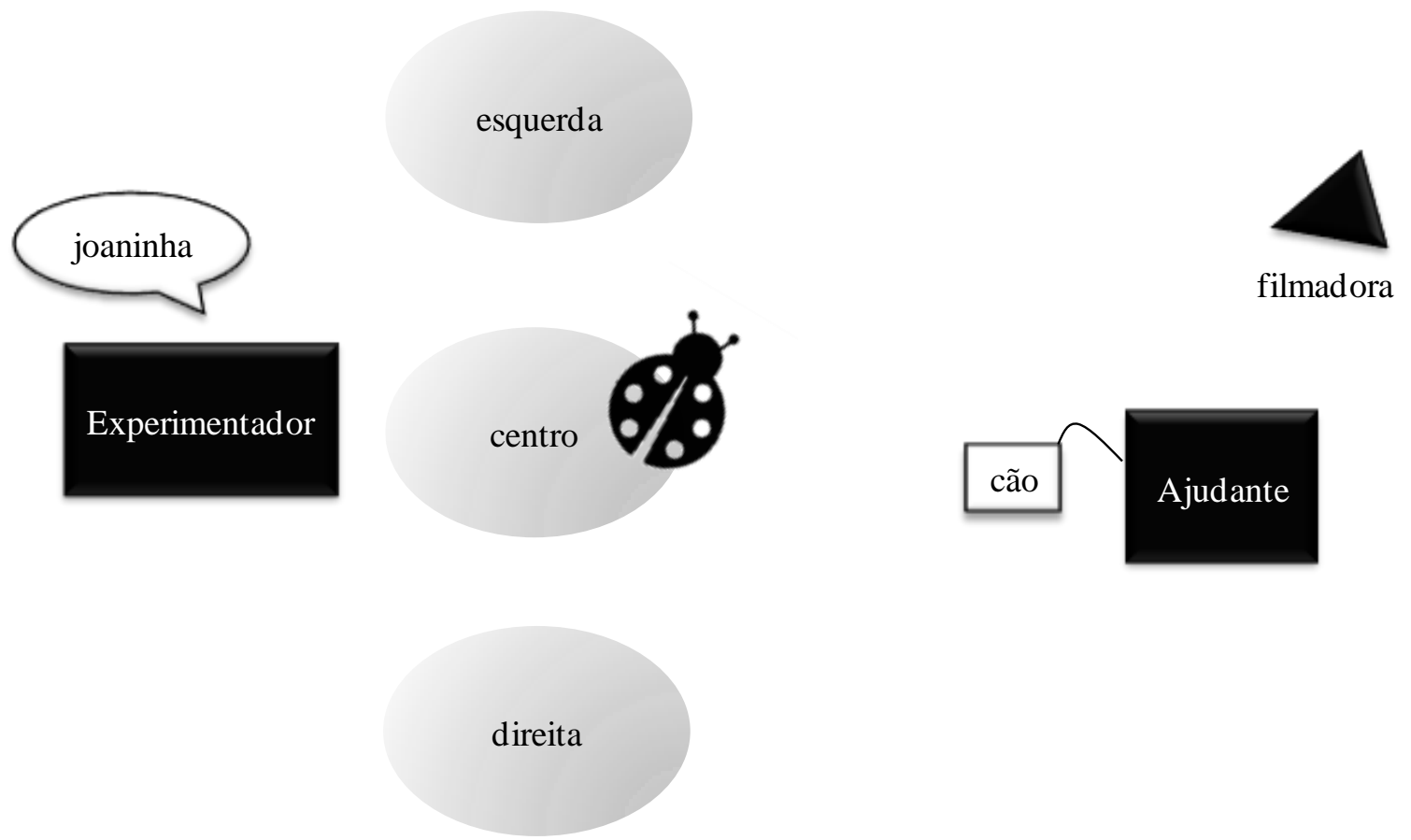

Figura 1. Disposições do experimentador, ajudante de pesquisa, filmadora e cão durante as sessões experimentais, bem como possíveis posições dos objetos. Neste exemplo, a instrução falada indicava a seleção do objeto "joaninha", que se encontrava ao centro.

\section{Equipamentos e Materiais}

Os objetos familiares foram escolhidos de acordo com o contexto de domesticação dos animais. Para Xena, esses objetos foram joaninha e tênis (ambos de borracha); para Pity e Sally, bolinha e ossinho. Os nomes escolhidos também estavam de acordo com a forma como os objetos eram nomeados pelos donos antes do estudo. Os objetos não familiares para os testes de exclusão foram construídos a partir de sucata, nomeados arbitrariamente pelo experimentador e eram inodoros e insípidos. Foi também utilizada uma filmadora digital para o registro das sessões.

\section{PROCEDIMENTO}

\section{Modelagem da Resposta}

As respostas requeridas nas tarefas exigiam que o cão se aproximasse de um de dois objetos disponibilizados em cada tentativa, após o experimentador dizer o nome do objeto requerido. Como esta resposta poderia não existir no repertório do cão, algumas sessões para verificação e possível modelagem da resposta foram inseridas antes do procedimento propriamente dito. Estas sessões também tinham o propósito de familiarização do cão com o experimentador e ajudante, bem como com a situação experimental.
A modelagem de tais respostas foi realizada da seguinte maneira: o experimentador colocava inicialmente apenas um objeto na frente do cão e fazia movimentos com ele, dizendo "Cadê o (nome do objeto)?". O cão era mantido na coleira e segurado pelo ajudante de pesquisa e somente após o posicionamento do objeto e apresentação da instrução, era liberado para responder. A resposta de se mover até o objeto e tocá-lo era reforçada com um pedaço de alimento, carinho e incentivos verbais. Considerava-se um erro caso o animal não se aproximasse dos estímulos, não o tocasse ou mesmo emitisse quaisquer respostas incompatíveis com a resposta correta, como, por exemplo, não se dirigir para nenhum dos estímulos. Neste caso, a tentativa era repetida: o animal era conduzido até a posição inicial e o mesmo estímulo era solicitado.

O movimento do objeto foi sendo esvanecido, até que, diante da solicitação, o cão se dirigisse ao objeto e o tocasse. A instrução também foi gradualmente reduzida, tornando-se mais sucinta, passando de "Cadê o (nome do objeto)?" a apenas "(nome do objeto)". Quando a resposta de se dirigir ao objeto passou a ocorrer consistentemente, foi introduzido um segundo objeto, aproximando-se mais da situação de treino e teste, porém com duas diferenças: o experimentador poderia fornecer dicas sobre qual estímulo deveria ser 
escolhido, e a resposta exigida pelo animal não implicava na correspondência correta entre nome e objeto, isto é, apenas se aproximar de um dos objetos era considerado correto, ainda que não fosse este o nome ditado pelo experimentador. As dicas fornecidas (como estalar os dedos sobre ou bater com o dedo no objeto) foram gradualmente retiradas ao longo das sessões de modelagem até que o animal escolhesse um dos objetos sem nenhuma dica durante nove tentativas consecutivas.

O critério para que a resposta fosse considerada modelada era a realização de um número mínimo de três sessões de doze tentativas cada: uma com apenas a apresentação de um objeto, a segunda com apresentação dos dois objetos e com dica e a terceira, também com a apresentação de dois objetos, com três tentativas com dica e as nove restantes sem dica.

\section{Treino de Discriminação Condicional}

O treino de discriminação dos estímulos foi dividido em três diferentes etapas, com sessões experimentais contendo12 tentativas cada. O critério de aprendizagem em cada etapa era de $80 \%$ de acertos em duas sessões consecutivas. A primeira etapa consistiu em duas sessões com apresentação de tentativas de esco- lha com um só estímulo (S1 na primeira sessão e S2 na segunda) diante da solicitação verbal do mesmo, variando-se sua posição de apresentação (esquerda, centro e direita).

$\mathrm{Na}$ segunda e terceira etapas, os dois estímulos foram apresentados concomitantemente. $\mathrm{Na}$ segunda etapa, apesar de haver dois estímulos disponíveis, apenas um deles era requisitado em cada sessão, ou seja, na primeira sessão somente $\mathrm{S} 1$ era requisitado, enquanto que na segunda sessão, requeria-se somente S2. Apenas na terceira etapa foi incluída a randomização gradual de apresentação de cada estímulo, primeiro com a apresentação de seis tentativas de $\mathrm{S} 1$, seguidas por seis tentativas com $\mathrm{S} 2$ ( $1^{\mathrm{a}}$ sessão); em seguida três tentativas com cada estímulo, até completar $12\left(2^{\mathrm{a}}\right.$ sessão), e, finalmente apresentação das tentativas aleatorizadas de escolha por S1 e S2 ( $3^{\mathrm{a}}$ sessão). A progressão do animal para as diferentes etapas de treino acontecia à medida que era atingido o critério de aprendizagem em cada etapa. A Tabela 1 descreve a organização de cada etapa do treino, com representação gráfica de cada modelo ditado em cada sessão, cada objeto apresentado ao animal como estímulos de comparação e o número de comparações utilizado em cada uma das sessões.

Tabela 1

Organização das Etapas do Treino de Discriminação Condicional

\begin{tabular}{|c|c|c|c|c|}
\hline Etapa & Sessão & Modelo & Comparações corretos em cada tentativa & $\mathrm{n}^{0}$ de comparações \\
\hline \multirow{2}{*}{1.} & 1.1. & $\mathbf{0}$ & 000000000000 & 1 \\
\hline & 1.2. & $\mathbf{\square}$ & 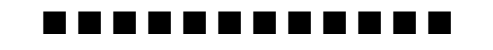 & 1 \\
\hline \multirow{2}{*}{2.} & 2.1. & $\mathbf{0}$ & 000000000000 & 2 \\
\hline & 2.2. & $\mathbf{\square}$ & 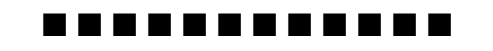 & 2 \\
\hline \multirow{3}{*}{3.} & 3.1. & $\mathbf{0}$ & $\circ \circ 0000 \square \square \square \square \square \square$ & 2 \\
\hline & 3.2. & $\mathbf{O a}$ & $000 \square \square \square 0000 \square \square$ & 2 \\
\hline & 3.3.* & on & $000 \square \square 000 \square 000$ & 2 \\
\hline
\end{tabular}

Em caso de erro em três tentativas consecutivas com o mesmo estímulo, eram utilizados procedimentos de correção que consistiam no uso de dicas sociais (apontar para o objeto correto). Após o procedimento de correção, o animal passava para a tentativa subsequente. As sessões em que haviam sido utilizados procedimentos de correção eram desconsideradas para o cálculo do critério de aprendizagem. Caso o animal não atingisse o critério em 24 sessões consecutivas na linha de base (i.e. 12 vezes o critério de aprendizagem), sua participação no procedimento era encerrada. 


\section{Teste de Exclusão I - "pafe"}

Após o treino, os animais foram submetidos a um teste de exclusão. $\mathrm{O}$ teste foi composto por 12 tentativas, oito de treino, que envolviam apenas a apresentação e solicitação de estímulos já apresentados durante o treino (tentativas de linha de base), e outras quatro de teste, envolvendo a apresentação e solicitação de um estímulo não familiar, nomeado de "pafe". A primeira metade do teste envolvia apenas tentativas de linha de base. As seis tentativas restantes misturavam tentativas de teste e de linha de base ("pafe" era solicitado nas tentativas de número sete, oito, 11 e 12).

Em caso de acerto, o animal tinha acesso ao reforçador alimentar e carinho. Em caso de erro, os reforçadores não eram apresentados e uma nova tentativa tinha início, sem a utilização de nenhum procedimento de correção.

O critério para que se considerasse o responder por exclusão como consistente foi a apresentação da resposta característica do responder por exclusão em pelo menos, três das quatro tentativas, ou seja, diante da verbalização "pafe" e da disponibilização de um objeto não familiar, junto a outro familiar, a seleção do não familiar.

\section{Teste com Dicas Contrárias à Aprendizagem Prévia}

Caso os animais atingissem o critério do Teste de Exclusão I, eram introduzidas tentativas de teste com dicas contrárias a este desempenho, isto é, direcionadas para o estímulo experimentalmente incorreto. Esse treino teve como objetivo avaliar como as duas fontes de controle incompatíveis (dicas sociais versus aprendizagem anterior) influenciariam o responder do animal, quando apresentadas concomitantemente.

Assim, eram apresentadas tentativas similares àquelas do teste de exclusão, ou seja, algumas tentativas com solicitação do estímulo "pafe" e outras tentativas com solicitação dos estímulos do treino de discriminação condicional, com o diferencial de que, nestas sessões, o experimentador fornecia dicas direcionadas para o estímulo visual diferente do estímulo auditivo ditado.

A dica também se modificava ao longo da sessão, ficando cada vez mais evidente. Assim, nas primeiras quatro tentativas, a dica consistia em olhar (Dica 1) para o estímulo contrário àquele que estava sendo ditado; nas próximas quatro tentativas, o experimentador virava a cabeça na direção do estímulo incorreto (Dica 2); e, nas tentativas restantes, a dica consistia em apontar para o objeto (Dica 3).
Houve também uma diferença na aplicação do procedimento entre os dois animais: Para Pity, os três tipos de dicas foram inseridas em todas as tentativas, como os modelos familiares e também com os não familiares, para Xena, foram introduzidas as Dicas $2 \mathrm{e}$ 3 nas tentativas com o modelo não familiar. Isso ocorreu devido a necessidade de abreviar de forma repentina o tempo final da coleta de dados e a subsequente opção pelo uso de dicas mais diretas.

\section{Teste de Exclusão II - "xipiti"}

Antes desta fase, foi realizada uma sessão de treino com os dois estímulos familiares treinados anteriormente, em tentativas alternadas e sem critério de aprendizagem, apenas para garantir a manutenção do desempenho treinado. Esta sessão não foi computada na sessão Resultados.

Após esta sessão, um segundo teste de exclusão foi realizado com o objetivo de avaliar possíveis influências do procedimento de dica contrária sobre o desempenho previamente aprendido dos animais: tanto a seleção de objetos familiares quanto o responder por exclusão, com o objeto novo. Este teste era idêntico ao primeiro teste de exclusão, porém um estímulo completamente novo foi inserido no lugar de "pafe", sendo nomeado de "xipiti". A definição da resposta correta e os estímulos familiares foram os mesmos do Teste de Exclusão I, assim como o arranjo das tentativas.

\section{RESULTADOS \\ Modelagem da Resposta}

A resposta de aproximação aos estímulos foi modelada com todos os animais de acordo com o esperado no procedimento. Como resultado, todos os três cães aprenderam a resposta, ainda que a partir de diferentes números de tentativas. O número de tentativas e sessões necessárias para tanto não foi considerado, sendo apenas garantido que o cão não iniciasse o treino antes de atingir o critério estipulado.

\section{Treino de Discriminação Condicional}

Nestas sessões, dois dos três cães alcançaram o critério. A participação de Sally foi encerrada após 24 sessões consecutivas sem atingir o critério de aprendizagem estipulado, mesmo com a inserção de modificações no procedimento.

Com relação aos demais cães, a Tabela 2 apresenta, em cada etapa do procedimento, a quantidade de sessões necessárias para atingir o critério de aprendizagem e a porcentagem média de acertos por sessão. 
Ainda que as duas participantes tenham atingido o critério de aprendizagem (80\% de acerto em duas sessões consecutivas) em todas as etapas do treino de discriminação condicional, pode-se perceber que Xena precisou de mais sessões para alcançar o critério de aprendizagem e cometeu mais erros que Pity, ainda que tenha sido uma diferença pequena.

\begin{tabular}{|c|c|c|c|c|}
\hline \multirow{2}{*}{ Etapa } & \multicolumn{2}{|c|}{$\mathrm{N}^{0}$ de sessões realizadas } & \multicolumn{2}{|c|}{$\%$ média de acertos por sessão } \\
\hline & Pity & Xena & Pity & Xena \\
\hline 1. & 2 & 2 & 100 & 100 \\
\hline 2. & 16 & 20 & 81,4 & 80,6 \\
\hline 3. & 12 & 18 & 79,5 & 68,5 \\
\hline
\end{tabular}

\section{Teste de Exclusão I - "pafe"}

A Tabela 3 apresenta o desempenho dos animais, durante esta fase do experimento. Em resumo, nas tentativas com estímulos familiares, ambas participan- tes apresentaram respostas corretas nas primeiras tentativas, porém seu desempenho caiu ao longo do teste, com dois erros para ambas as cachorras.

Tabela 3

Desempenho dos Animais no Teste de Exclusão para o Estímulo Novo ("pafe") e Familiares (bolinha e ossinho para Pity, joaninha e tênis para Xena)

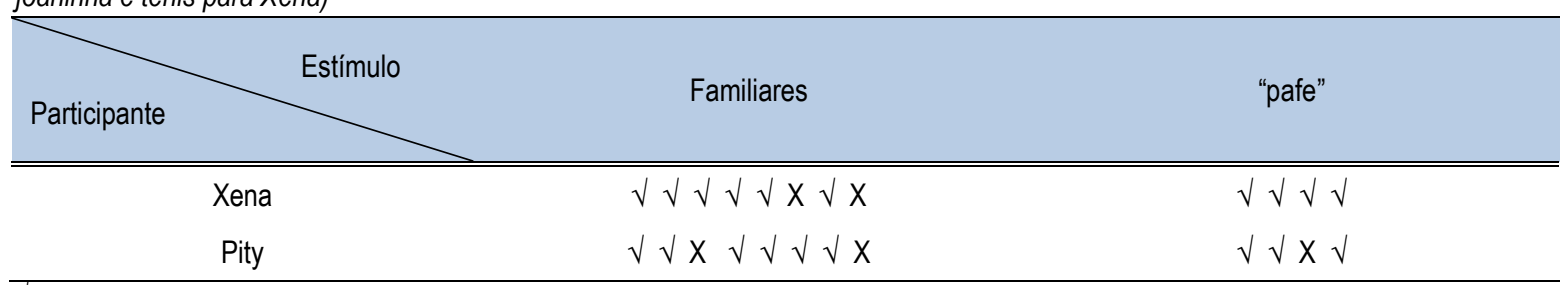

$\sqrt{\text { : respostas corretas }}$

$\mathrm{X}$ : respostas incorretas

Das quatro tentativas em que era solicitado o novo estímulo, "pafe", as duas participantes responderam corretamente ao estímulo novo na primeira tentativa em que este foi apresentado e continuaram a responder a ele na maior parte delas: Xena não teve nenhum erro, enquanto Pity cometeu apenas um erro.

\section{Teste com Dicas Contrárias à Aprendizagem Prévia}

A Figura 2 apresenta os dados do teste com inserção de dicas sociais contrárias ao modelo ditado, separados por estímulo, para cada uma das dicas. A figura mostra o controle exercido pelas duas fontes presentes: o modelo ditado e a dica social contrária a este modelo. As fontes de controle mutuamente excludentes foram representadas pelo preenchimento das barras horizontais, de forma que preenchimento escuro indi- ca controle pelo modelo ditado e preenchimento claro, pela dica contrária.

Assim, como se pode ver, a dica contrária exerceu forte influência no comportamento de ambas as cachorras quando o estímulo era familiar, e especialmente nas ocasiões em que a dica era mais saliente: apontar para o estímulo (Dica 3). De fato, em todas as tentativas com este tipo de dica, os estímulos familiares (S1 e S2) foram selecionados de acordo com a dica e não com o modelo ditado.

Já em relação ao estímulo "pafe", os dados mostram que o controle da dica social contrária não foi tão forte, com Xena tendo seguido o modelo ditado em todas as tentativas envolvendo "pafe" e Pity, na maior parte delas. 


\section{Teste de Exclusão II - "xipiti"}

Neste segundo teste de exclusão, o desempenho das duas cachorras mostrou declínio: ambas cometeram quatro erros. Nas quatro tentativas em que era solicitado o novo estímulo, "xipiti", o desempenho de ambas foi idêntico ao encontrado no primeiro teste, com nenhum erro para Xena e apenas um erro para Pity. A Tabela 4 apresenta o desempenho dos animais durante este teste.

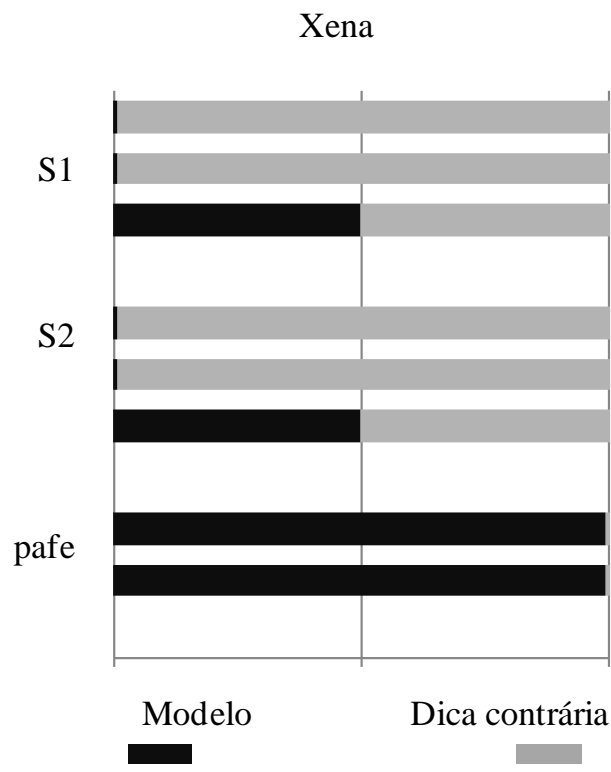

Dica 1: olhar em direção

Dica 2: virar a cabeça

Dica 3: apontar
Pity

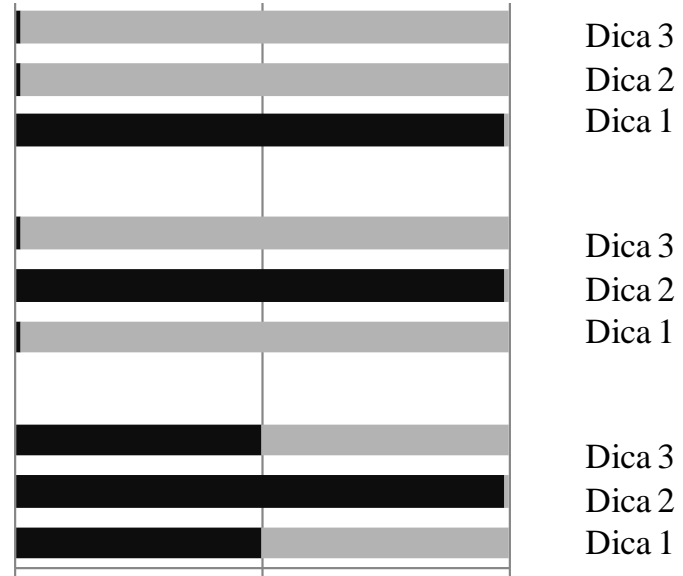

Modelo

Dica contrária
S1: Para Xena: joaninha Para Pity: bolinha
S2: Para Xena: tênis

Para Pity: ossinho

Figura 2. Distribuição de respostas no teste com dicas contrárias à aprendizagem prévia de Xena (gráfico à esquerda) e Pity (gráfico à direita). Para cada cão, a parte superior do gráfico representa os testes com estímulos familiares, e a parte inferior, aqueles com o estímulo "pafe". As barras representam os tipos de dicas. As partes escuras das barras representam a porcentagem de vezes o cão selecionou o estímulo de acordo com o modelo verbal dado pela experimentadora, enquanto que partes claras indicam a porcentagem de respostas sob controle da dica social contrária à instrução.

Tabela 4

Desempenho dos Animais no Teste de Exclusão para o Estímulo Novo ("xipiti") e Familiares (bolinha e ossinho para Pity, joaninha e tênis para Xena)

\begin{tabular}{|c|c|c|}
\hline Participante & Familiares & "xipiti" \\
\hline Xena & $\sqrt{ } \sqrt{ } x \sqrt{ } x x x$ & $\sqrt{ } \sqrt{ } \sqrt{ }$ \\
\hline Pity & $\sqrt{ } \sqrt{ } x \sqrt{ } x \sqrt{ } x$ & $\sqrt{ } \sqrt{ } \times \sqrt{ }$ \\
\hline
\end{tabular}

$\sqrt{ }$ : respostas corretas

$\mathrm{X}$ : respostas incorretas

\section{DISCUSSÃO}

O presente estudo pretendeu avaliar influência de dicas sociais humanas no desempenho de três cães em tarefas de seleção de objetos familiares e seleção por exclusão.

Os dados do teste de exclusão apontaram que, em consonância com outros estudos (Hare e cols., 2002; 
Bräuer, Kaminski, Riedel, Call, \& Tomasello, 2006, entre outros), em especial o de Kaminski e colabordores (2004), precursor neste tipo de pesquisa, os sujeitos pareceram demonstrar o responder por exclusão, caracterizado pela seleção da alternativa correta, por exclusão das demais (Dixon, 1977).

Os resultados encontrados mostraram que as duas cachorras que conseguiram concluir o treino preliminar escolheram o objeto novo já na primeira tentativa dos dois testes de exclusão realizados, o que mostra claramente que o objeto novo exerceu controle sob o comportamento dos animais. Como os testes eram realizados com reforçamento, de fato, é somente possível afirmar que existiu o controle por exclusão na primeira tentativa de cada teste.

É importante ressaltar aqui que o treino empregado para estabelecer a linha de base e testar o responder por exclusão, um procedimento de discriminação condicional auditivo-visual, foi bastante efetivo e econômico, de forma que os dois animais, que não tinham experiência prévia no comportamento de buscar um objeto pelo nome, aprenderam tal comportamento e também mostraram sucesso na demonstração do responder por exclusão, a partir de um número reduzido de tentativas. De fato, esta é uma contribuição importante deste estudo, já que os cães de estudos anteriores têm precisado de muito mais tentativas para demonstrar os mesmos comportamentos. Por exemplo, para atingir o desempenho de responder por exclusão de Rico (que já era treinado desde poucos meses de idade a buscar objetos pelo nome), Kaminski e colegas (2004) empregaram uma quantidade de tentativas muito maior: dez sessões de oito tentativas cada.

Mesmo com poucas tentativas, o controle pelo objeto novo parece ter sido tão bem estabelecido que, mesmo com a introdução de um procedimento especialmente delineado para desfazê-lo (o teste com dicas sociais contrárias), o desempenho dos cães se manteve fortemente guiado pelo objeto novo na maior parte das tentativas, tanto durante o teste com dicas sociais quanto no segundo teste de exclusão, com o novo objeto, "xipiti".

Contrariamente a este resultado, os dados do teste com dica social envolvendo objetos do contexto de domesticação dos animais mostraram que, nestes casos, as dicas exerceram um controle mais forte sobre comportamento dos cães do que a instrução ditada, em especial nos casos em que o gesto era mais saliente: apontar para o objeto. Nestas ocasiões, os dois cães se guiaram pela dica em $100 \%$ das tentativas. Este dado está de acordo com a literatura que demonstra a influência das dicas sociais humanas na aprendizagem canina (Hare e cols., 2002; Call e cols., 2003; Hare \& Tomasello, 2005; McKinley, \& Sambrook, 2000; Miklósi, Topál \& Csányi, 2001; Miklósi, Polgárdi, Topál, \& Csányi, 2000; Udell \& Wynne, 2008).

Esta deterioração do controle antes demonstrado pelos animais se manteve, inclusive, no último teste de exclusão, quando o desempenho dos animais caiu bastante em comparação ao primeiro teste de exclusão nas tentativas em que o modelo era um estímulo familiar.

Para analisar mais a fundo estes dados, é preciso realizar uma análise do que os resultados necessariamente mostram e o que deixam margem à interpretação.

É inquestionável o controle exercido pelos objetos não familiares no comportamento dos animais, tanto nos testes de exclusão quanto no procedimento com dica contrária. Contudo, algumas características do procedimento deixam em aberto a questão sobre qual tipo de controle de fato foi exercido pelo objeto novo, isto é, se o fenômeno observado foi genuinamente exclusão ou se existem outras possibilidades explicativas.

Uma possível explicação para o desempenho praticamente sem falhas nos testes de exclusão pode ser o controle exercido pela novidade do estímulo, ainda que várias medidas tenham sido tomadas para prevenir esta interferência, como a quantidade de tentativas nos testes com os estímulos novos (quatro repetições), e a inserção de um novo estímulo,"xipiti", ao final do procedimento com "pafe", que poderia já ter se tornado familiar ao longo das tentativas.

Estudos futuros devem incluir testes de controle pela novidade na tentativa de excluir explicações alternativas. Um teste que permitiria distinguir entre controle por exclusão ou por novidade seria introduzir tentativas de seleção, em que o modelo ditado fosse um estímulo familiar e, entre os estímulos de comparação negativos, inserir "pafe" ou "xipiti" ou um estímulo completamente novo. As tentativas de linha de base incluídas ao longo do teste de exclusão não foram suficientes para lidar com tal controle, uma vez que nessas tentativas tanto o estímulo modelo quanto os estímulos de comparação eram familiares. Outra possibilidade seria testar os dois estímulos novos, "pafe" e "xipiti" na mesma tentativa, solicitando alternadamente cada um dos estímulos.

Aust e colegas (2008) realizaram ainda outro teste, incluindo um terceiro estímulo juntamente com o teste por exclusão, tendo por modelo o estímulo anterior. De acordo com esses autores responder a um dos 
estímulos anteriores quando a instrução era essa (no caso, "pafe" ou "xipiti") seria considerada uma legítima aprendizagem por exclusão (porque esses estímulos tinham adquirido função positiva, por exclusão) e responder ao terceiro estímulo desconhecido seria considerado como preferência/controle pela novidade e/ou uma resposta ao acaso (porque "pafe" ou "xipiti" não tinham adquirido função positiva).

Há que se ressaltar que a possibilidade de controle pela novidade não impede o controle pela exclusão. De fato, as respostas de ambos os cães mostram que a escolha por "pafe" e "xipiti" pode ter acontecido sob controle de uma provável combinação destas duas fontes, exclusão e novidade do estímulo.

Outro ponto importante diz respeito ao motivo de as dicas sociais, que não exerceram influência na escolha pelo objeto novo, terem conseguido romper com o controle exercido pelo nome do objeto conhecido, provavelmente uma relação já muito fortalecida no repertório dos animais mesmo antes do experimento.

Uma primeira possibilidade se relaciona com o treino de seleção realizado. Nenhum dos animais tinha história anterior de adestramento, o que fez com que o treino inicial de seleção fosse bastante custoso e a instalação da resposta de dirigir-se até o objeto nomeado levasse bastante tempo. De fato, um dos cães, mesmo após uma quantidade muito grande de treino, não conseguiu atingir o critério para este estágio do procedimento ( $80 \%$ de acertos em duas sessões consecutivas). Da mesma forma, ainda que o critério neste treino tenha sido atingido para os outros dois cães, é possível que a resposta condicional (frente ao nome do objeto, dirigir-se a ele) não tenha sido suficientemente estabelecida, de forma que, diante de uma indicação mais evidente (o gesto), as duas fontes de controle tenham entrado em conflito e o animal tenha escolhido aquela mais forte em seu repertório, as instruções não verbais.

Esta explicação suporta, inclusive, a hipótese anterior, de que o controle exercido pelo objeto novo possa ter sido, ao menos em parte, influenciado pelo aspecto de novidade do estímulo, não pela exclusão em si. Isto porque, quando se assume que o controle da seleção dos objetos não familiares aconteceu por exclusão, tem-se que, diante de duas fontes de controle conflitantes, uma apenas recentemente estabelecida (exclusão) e outra já presente no repertório do animal há mais tempo (gestos humanos), a fonte de controle mais recente teria exercido o controle, e não o oposto, como ocorreu com os objetos familiares. Esta explicação parece pouco provável.
Porém, ao se considerar a influência de controle pela novidade, tem-se que este é um controle provavelmente bastante fortalecido no repertório do animal previamente ao experimento, de forma que a fonte de controle social (gestos humanos) teria que entrar em oposição não à exclusão apenas, mas à novidade do estímulo, ou mesmo à novidade somada à exclusão (no caso de uma fonte de controle combinada), e, neste caso, a rejeição da dica social se torna bem mais plausível.

Por fim, há que se ressaltar que todo o experimento foi realizado como uma adaptação para a situação natural (na casa dos donos dos animais) de procedimentos já consagrados na pesquisa psicológica animal em laboratório. Assim, ainda que todos os cuidados possíveis tenham sido tomados (como as sessões de familiarização do cão com o experimentador, a filmagem dos treinos e testes, e a retirada do dono do animal da situação experimental), não se pode excluir a possibilidade de alguma interferência desconhecida nos dados.

\section{CONCLUSÃO}

Em resumo, o presente estudo pretendia verificar e replicar dados relativos à aprendizagem de escolha por exclusão em cães, a partir de um procedimento de discriminação condicional entre objetos e seus respectivos nomes ditados. Os resultados mostraram confiavelmente o controle pelo objeto novo, ainda que não se possa separar com clareza o controle por exclusão da influência da novidade do estímulo.

Apoiado nisso, pretendeu-se, então, avaliar empiricamente a influência de dicas sociais humanas no desempenho dos cães nas tarefas de escolha por exclusão, inserindo-as de forma oposta à aprendizagem já estabelecida. Esta estratégia foi extremamente eficiente em romper com o controle já estabelecido pelos nomes dos objetos familiares, uma vez que, ao ser introduzida a dica contrária, o responder dos cães deixou de ser estável, mostrando a influência humana no comportamento dos cães.

Para refinar o procedimento, futuras pesquisas deverão estender os treinos de seleção iniciais, e os testes de exclusão deverão incluir tentativas com múltiplos exemplares, além de outras, de controle pela novidade.

Ainda que de caráter exploratória, a investigação experimental realizada do controle exercido por diversos aspectos do ambiente no comportamento destes animais pôde trazer vários dados importantes para $\mathrm{o}$ campo da aprendizagem canina, e contribuir com algumas discussões presentes na área.

Interação Psicol., Curitiba, v. 16, n. 2, p. 173-183, jul./dez. 2012 


\section{REFERÊNCIAS}

Aust, U., Range, F., Steurer, M., \& Huber, L. (2008). Inferential reasoning by exclusion in pigeons, dogs, and humans. Animal Cognition, 11, 587-597.

Bräuer, J., Kaminski, J., Riedel, J., Call, J., \& Tomasello, M. 2006. Making inferences about the location of hidden food: Social dog, causal ape. Journal of Comparative Psychology, $120,38-47$.

Call, J., Bräuer, J., Kaminski, J., \& Tomasello, M. (2003). Domestic dogs (Canis familiaris) are sensitive to attentional states of humans. Journal of Comparative Psychology, 117, 257-263.

Costa, A. R. A. (1999). Mapeamento simbólico emergente em indivíduos com desenvolvimento normal e em portadores de Síndrome de Down (Dissertação de Mestrado). Universidade Federal de São Carlos.

Dixon, L. S. (1977). The nature of control by spoken words over visual stimulus selection. Journal of Experimental Analysis of Behavior, 27, 433-442.

Ferrari, C., de Rose, J. C. C., \& McIlvane, W. J. (1993). Exclusion vs. selection training of auditory-visual conditional relations, Journal of Experimental Child Psychology, 56, 49-63.

Hare, B., Brown, M., Williamson, C., \& Tomasello, M. 2002. The domestication of social cognition in dogs. Science, 298, 16341636.

Hare, B., \& Tomasello, M. (2005). Human-like social skills in dogs? Trends in Cognitive Sciences, 9, 439-444.
Kaminski, J., Call, J., \& Fisher, J. (2004). Word learning in a domestic dog: Evidence for fast mapping. Science, 304, 1682.

McKinley, J., \& Sambrook, T. D. (2000). Use of human givencues by domestic dogs (Canis familiaris) and horses (Equus caballus). Animal Cognition, 3, 13-22.

Miklósi, Á., Polgárdi, R., Topál, J., \& Csányi, V. (2000). Intentional behaviour in dog-human communication: An experimental analysis of the "showing" behaviour in the dog. Animal Cognition, 3, 159-166.

Miklósi, Á., Topál, J., \& Csányi, V. (2001). Comprehension of human communicative signs in pet dogs (Canis familiaris). Journal of Comparative Psychology, 15, 122-126.

Tomasello, M. (1999). The cultural origins of human cognition. Cambridge, MA: Harvard University Press.

Udell, M. A. R., \& Wynne, C. D. L. (2008). A review of domestic dogs' (Canis-familiaris) human-like behaviors: Or why behavior analysts should stop worrying and love their dogs. Journal of the Experimental Analysis of Behavior, 89, 247-261.

Vila, C., Savolainen, P., Maldonado, J. E., Amorim, I. R., Rice, J. E., Honeycutt, R. L., Crandall, K. A., Lundeberg, J., \& Wayne, R. K. (1997). Multiple and ancient origins of the domestic dog. Science, 276, 1680-1687. 